Goldschmidt 2021 Abstract

https://doi.org/10.7185/gold2021.6836

\section{Response of weathering and erosion to the intense tectonic uplift of the South African Plateau during the Late Cretaceous: Preliminary insights.}

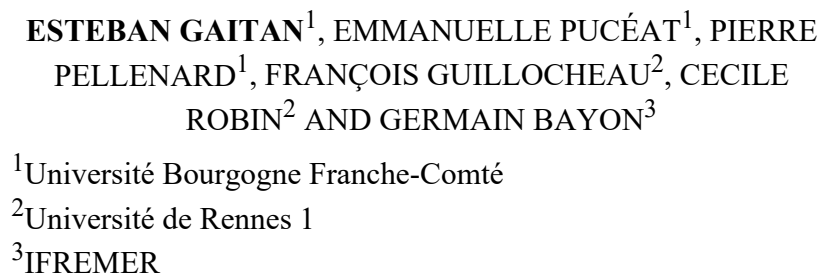

${ }^{1}$ Université Bourgogne Franche-Comté

${ }^{2}$ Université de Rennes 1

${ }^{3}$ IFREMER

Presenting Author: camilo-esteban_gaitan-valencia@etu.ubourgogne.fr

During the Late Cretaceous the South African Plateau experienced a period of uneven tectonic uplift. It started during the Turonian with an early pulse in the eastern margin, which increased the sediment accumulation rates in the western side, especially in the Orange and Cape basins. This was followed by a late uplift stage in the western margin during the Campanian, which similarly increased the sediment accumulation rates in the eastern side, particularly in the Transkei and Durban Basins. This occurred within a greenhouse climate and coincided with a marked global climate cooling during the Late Cretaceous. Sediment budget calculations have been performed for this system, but quantitative constrains on the long-term response of the denudation processes to this tectonic event and climatic variations remain unsolved. In this study, we combine two geochemical techniques to determine the intensity of chemical weathering and physical erosion. We use a new proxy of chemical weathering intensity, the $\Delta_{\mathrm{Hf}}$ based on coupled Lu-Hf and $\mathrm{Sm}-\mathrm{Nd}$ isotopic systems in clay fractions [1]. This technique is joint with X-ray Diffraction to determine the concomitant evolution of clay mineralogical assemblages thus tracking the progress of physical erosion. Both methods are applied on sediments from DSDP sites 361 and 249 (Fig. 1). This new data set will be combined with published sediment budget [2] and climate records to discuss the links between uplift, margin denudation, chemical weathering and how they impact the accumulation rates of sediments in the nearby oceanic basins.

Figures

Fig. 1 Location of the IODP cores 361-249. Modified after [2]. References

[1] Bayon, G. et al. Environmental Hf-Nd isotopic decoupling in World river clays. Earth Planet. Sci. Lett. 438, 25-36 (2016).

[2] Baby, G., Guillocheau, F., Braun, J., Robin, C. \& Dall'Asta, M. Solid sedimentation rates history of the Southern African continental margins: Implications for the uplift history of the South African Plateau. Terra Nova 32, 53-65 (2020).

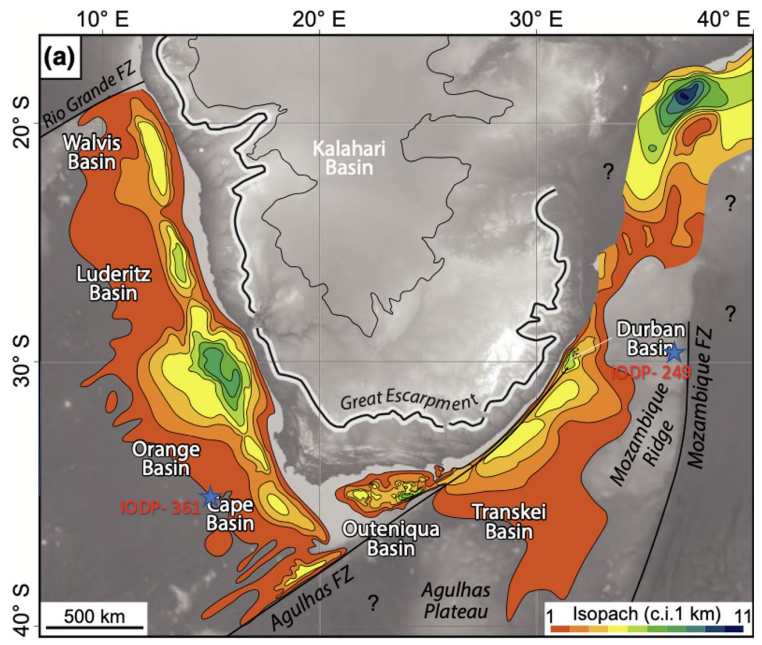

